\title{
ESTADO Y CLASES SOCIALES EN LA REVOLUCION ESPAÑOLA DE 1868
}

\author{
Por SALVADOR ForNER MUÑOZ
}

Universidad de Alicante

La revolución de 1868 ocupa un lugar de privilegio entre todos los movimientos revolucionarios del XIX español. Los numerosos análisis e interpretaciones que, sobre todo a partir del año $1968,{ }^{1}$ se han realizado sobre la misma contienen, dentro de su diversidad, una nota común: la singularidad del fenómeno revolucionario del sesenta y ocho.

Considerada como la más fuerte y fecunda en consecuencias conmoción política del siglo $\mathrm{XIX},{ }^{2}$ como el movimiento que rompe los valores tradicionales del revolucionarismo español ${ }^{3} \mathrm{o}$ como el reflejo tardío de las grandes revoluciones europeas de $1848,{ }^{4}$ la llamada revolución de septiembre de 1868 ha sido per-

1 El centenario de la revolución de 1868 dio lugar a un importante número de artículos y monografías sobre el tema. Una buena recopilación de dichos trabajos, hasta el año 1978, puede verse en GUERENA, J. L., El «sexenio revolucionarion en la historiografía, dentro de Historiografía española contemporánea, $X$ coloquio del Centro de Investigaciones Hispánicas de la Universidad de Pau, Madrid, 1980, págs. 147-174.

2 González, NAZARio, "Análisis, concepción y alcance de la revolución de 1868", Razón y Fe, Madrid, 1968, pág. 353.

3 Gómez Marin, J. A., "Alcance de los movimientos sociales en la revolución de 1868", Atlántida, 1968, pág. 567.

4 Los supuestos paralelismos entre el sesenta y ocho español y las revoluciones europeas de 1848 fueron señalados, inicialmente, por Fernández Almagro, insistiendo en esas posibles semejanzas otros autores como GómEZ Marín, J. A., Op. cit., pág. 569; GonzÁlez, NaZARIO, o. c., pág. 448; EIRAs RoEl, A., "Nacimiento y crisis de la democracia en España: la revolución de 1868", Cuadernos Hispanoamericanos, Madrid, 231, 1969, pág. 592. 
cibida en general por la historiografía española, sin diferencias de adscripción ideológica o de escuela, como un acontecimiento excepcional de nuestro siglo XIX que marca el inicio de una divisoria en la Historia Contemporánea de España. ${ }^{5}$ No hay duda de que la mucha mayor participación popular en el sesenta y ocho que en otros pronunciamientos anteriores y la característica única de dar lugar a un cambio dinástico confieren al movimiento septembrino una especificidad indiscutible que puede originar un cierto espejismo: el de considerar la revolución de 1868 como un acontecimiento cualitativamente distinto al resto de los movimientos revolucionarios y pronunciamientos del $\mathrm{XIX}{ }^{6}$

Un intento de comprensión de la auténtica naturaleza de la revolución del sesenta y ocho $-y$, por extensión, del sexenio revolucionario- debe pasar, a nuestro juicio, por el análisis de las clases sociales en conflicto, de las transformaciones en el seno del bloque en el poder, de las relaciones entre las clases sociales y la escena y el poder político y de los cambios en el aparato estatal. Para ello es preciso analizar, con anterioridad, las características de la forma de régimen del estado liberal español en los años que preceden a la revolución de 1868 .

Puede decirse que a partir de 1840 , concluida la guerra carlista, se produce la consolidación del estado liberal en España. La forma de régimen de dicho estado liberal es la monarquía isabelina cuyo desarrollo político está determinado por los tres pilares sobre los que la misma se sustenta: la Corona, el Ejército y los partidos dinásticos. ${ }^{7}$ El fundamento social de dicho régimen

José Luis Comellas llega a hablar del inicio de una nueva época histórica - la baja Edad Contemporánea - para designar el período que comienza el 27 de diciembre de 1874 (COMELLAS, J. L., "Génesis de la revolución del 68", Atlántida, VI, 1968, pág. 550).

6 La polémica acerca del carácter de revolución o de pronunciamiento del movimiento de 1868 ha sido referencia obligada en todos los trabajos sobre el tema y se ha revelado, a nuestro juicio, profundamente estéril e innecesaria. Mucho más interesantes son las precisiones de Fontana sobre el concepto de revolución y las distintas acepciones del termino (Vid. FonTANA, Cambio económico y actitudes políticas en la España del siglo XIX, Barcelona, 1980, págs. 99-105).

7 CarR, Raymond, España, 1808-1939, Barcelona, 1970, págs. 211-218. 
era la consolidación de un bloque en el poder constituido por los especuladores capitalistas, la burguesía industrial y bancaria, los grandes propietarios agrarios -en gran parte procedentes de la antigua aristocracia - y una cúspide militar ennoblecida. ${ }^{8}$ Dichos grupos sociales formaban lo que el liberalismo de izquierda no integrado en el sistema denominaba la oligarquía gobernante, es decir, unas quinientas familias - en el sentido amplio del término- que se distanciaban cada vez más del conjunto del pueblo y que habian adoptado unas formas de vida muy similares a las de la alta burguesía francesa de la época, deslumbrándose más, como dice Tuñón, ${ }^{9}$ por los negocios de los banqueros de Luis Felipe que por el desarrollo industrial inglés.

En su aspecto político el régimen de la monarquía isabelina estaba determinado por el papel preponderante de la Corona en el proceso de formación de la voluntad política, que hacía imposible la articulación de alternativas reales dentro del sistema. Como es sabido, las fuerzas políticas que apoyaron a la monarquía isabelina se aglutinaban en torno a dos modelos distintos de sistema político que en el fondo coincidían en lo fundamental. De un lado, el llamado liberalismo doctrinario, basado en la doble representación de dos instituciones - Corona y Cortesque detentan la soberanía y en el que, junto al poder ejecutivo, se otorga a la primera un nuevo poder, el poder moderador. ${ }^{10} \mathrm{De}$ otro lado, el liberalismo radical, que no reconoce más representación que la de las Cortes pero que incluye en sus formulaciones la facultad de la Corona de disolver éstas, con lo que, como ya se ha dicho, las diferencias de fondo con el modelo doctrinario son casi nulas, limitándose a la mayor o menor amplitud del censo electoral y a la mayor o menor extensión de las libertades formales.

Uno y otro modelo de liberalismo constituían, respectivamente, las bases de los dos grandes partidos integrados en el sistema: el moderado y el progresista. Flanqueando a estas dos

8 1976. págs. 6-9.

9 TUÑ́n DE LARA, M., Estudios sobre el siglo XIX español, Madrid, 1978, pág. 66.

10 ARtolA, M., La burguesia revolucionaria, Madrid, 1973, págs. 179-183. 
fuerzas, a derecha e izquierda, quedaban los movimientos de inspiración absolutista y la escisión progresista que daría orígen al Partido Demócrata, cuyo objetivo fundamental consistía en la consecución del sufragio universal y de las más amplias libertades democráticas. La exclusión de ambas fuerzas reducía, evidentemente, la base social del sistema, pero el problema de fondo del sistema isabelino no era éste, ni tampoco el de la enorme estrechez del cuerpo electoral; ${ }^{11}$ el gran problema es que la monarquía de Isabel II no aseguró siquiera la participación pacífica -y no por la vía del movimiento revolucionario- de fuerzas como el progresismo cuya integración resultaba básica para el mantenimiento del sistema.

La marginación del progresismo tenía el efecto de impedir el acceso a la escena política de importantes sectores sociales y de opinión que èran, además, por el propio desarrollo económico-social del país, los que presentaban unas mayores posibilidades de expansión. La experiencia de la Unión Liberal significó, de alguna manera, el intento de realizar una especie de apertura política que ensanchase la base del sistema sin que se produjesen rupturas profundas. Como proyecto político de centro, la Unión Liberal tuvo un éxito momentáneo entre 1858 y 1863. Pero la estabilidad política de esos años fue más la consecuencia del auge económico y de una cierta proyección hacia el exterior, que actuaba como aglutinante ideológico, ${ }^{12}$ que el resultado de una auténtica integración del progresismo. Más bien puede decirse que la participación subalterna de los progresistas fue motivo de la descomposición y progresiva radicalización del movimiento, con el triunfo, a partir de 1863, de las posiciones situadas más a la izquierda y el acercamiento hacia los demócratas con los que se sellaría el llamado Pacto de Ostende, en el verano de 1866, al que se sumaría más tarde la propia Unión

11 Con ser muy reducido el derecho al sufragio en España, en nada se diferencia de otros países europeos, como Inglaterra, que a pesar de ello consolidaron de manera muy efectiva la monarquia parlamentaria en el siglo XIX. A este respecto vid. MARTínez CuAdRAdo, M., "El horizonte político de la Revolución española de 1868", Revista de Occidente, VI, 1968, pág. 23.

" 12 En 1860 se produce la toma de Tetuán dentro de una perspectiva de colonialismo político, o de prestigio, más que de auténtico colonialismo económico. 
Liberal ante la imposibilidad de una apertura real del sistema, culminándose de esta forma el proyecto revolucionario que apuntaba directamente al destronamiento de Isabel II.

De lo dicho anteriormente puede llegarse a la conclusión de que una de las causas esenciales de la revolución de 1868 fue la progresiva reducción de la representación y de la participación en la escena política de partidos que representaban importantes intereses de determinados sectores de la burguesía y de otras clases intermedias. Esta cuestión debe ser, sin embargo, profundizada contestando a dos cuestiones fundamentales. La primera de ellas es la siguiente: ¿por qué esa falta de representación y de participación en la escena política mueve a esas clases a promover un cambio político en profundidad? La segunda: ¿por qué ese cambio político se resuelve a través del desencadenamiento de un movimiento revolucionario con importante participación popular que trastoca profundamente el sistema político?

Aunque la respuesta al primer interrogante parezca obvia a primera vista, conviene recordar que no hay un paralelismo exacto entre el interés y la hegemonía social de una clase y su presencia dominante en la escena política. Como ejemplos basta con citar el caso de la burguesía industrial inglesa que siendo, después de 1832, la clase hegemónica en Gran Bretaña ve realizados sus intereses a través de la participación en la escena política de la aristocracia terrateniente, o el caso más reciente de la pequeña burguesía alemana durante el nazismo que, como clase reinante, ocupa la escena política realizando los intereses del gran capital financiero. ${ }^{13}$

Antes de intentar contestar a la primera pregunta que planteamos conviene hacer una serie de consideraciones sobre el proceso revolucionario que se inicia en septiembre de 1868. Hay que tener en cuenta, en primer lugar, que estamos ante un proceso en el que no se produce ninguna trasformación en la forma del estado y mucho menos en el tipo de estado. Es decir, se trata de un proceso en el que sólo se producen cambios en el sistema

13 Vid. Poulantzas, N., Poder político y clases sociales en el estado capitalista, Madrid, 1972, pág. 324; del mismo autor, Fascismo y dictadura, la III Internarional frente al fascismo, Madrid, 1973, págs. 290-292. 
político y un cambio en la forma de régimen: la breve experiencia republicana. La única duda viene planteada por el período del año 1874 que se inicia tras el golpe de Pavía y la disolución de las Cortes, pero resulta enormemente aventurado pensar que - a pesar de la anormalidad parlamentaria - dicho período supusiese un cambio en la forma del estado liberal. ${ }^{14}$ Hay, en segundo lugar, una cuestión clave para entender las auténticas características de la revolución de 1868: la aparición en el Gobierno, tras el golpe de Pavía, de los principales hombres del sesenta y ocho, como Serrano, Topete o Cristino Martos, ${ }^{15}$ de tal manera que tanto el golpe de Pavía como la posterior restauración canovista no son, como pudiera parecer a primera vista, el fracaso del movimiento revolucionario iniciado en 1868 , sino más bien la culminación de dicho movimiento, siendo una buena prueba de ello los cași cincuenta años de estabilidad política que siguen al golpe de Martínez Campos. ${ }^{16}$

La constatación del no fracaso de la revolución de 1868 y la visión de la misma como un proceso que culmina en el año $1874^{17}$ son, desde nuestro punto de vista, cuestiones de capital importancia ya que, a partir sobre todo de 1968, ha sido casi una constante en la historiografía española la consideración de la revolución del sesenta y ocho como una revolución burguesa fracasada, ${ }^{18}$ con la consiguiente conclusión de la incapacidad de la burguesía española para haber cumplido su misión histórica,

Más bien se trata de un período puente entre la República y la Restaưración o, en palabras de Nazario González, un régimen indeçiso de transición (o. c., pág. 337).

Una relación bastante completa de los hombres que ocupan el poder político entre 1868 y. 1874 puede verse en Tuñón , M., Estudios sobre el siglo XIX..., págs. 98-101.

Estabilidad, por supuesto, relativa pero indicadora al menos de un cierto equilibrio en el bloque en el poder que sólo se rompe en el año 1923.

17 Cf. Fontana, J., o. c., pág. 141.

18 Tras el olvido o la tergiversación que se produce a partir de 1940, los años sesenta, especialmente a partir del centenario, supusieron un paso hacia adelante en el conocimiento y las interpretaciones de la revolución de 1868, pero en las que predominó esa visión de fracaso. Cf., entre otros, JUTGLAR, Ideologías y clases en la España Contemporánea, I, Madrid, 1968, págs. 291 ss.; Tuñón, M., o. c., pág. 87; Catalinas, J. L. y Echenagusía, J., La 1. a República, reformismo y revolución social, Madrid, 1973, pág. 26. 
esto es, realizar su revolución. Esa interpretación encierra, a nuestro juicio, dos errores a los que conviene referirse. El primero de ellos deriva de la ambigüedad del término revolución burguesa y de la no diferenciación de lo que debe entenderse como revolución social, en el más amplio sentido del término, y revolución política protagonizada por la burguesía o por un sector de la misma. ${ }^{19}$ Tal confusionismo procede de una visión excesivamente instrumentalista del estado que es concebido como herramienta de una clase social que dispone libremente de él sin ningún tipo de mediaciones desde el momento en que esa clase detenta la hegemonía social, lo que equivaldría a considerar imposible una acción revolucionaria de dicha clase para ocupar la escena política. Esa visión olvida, en primer lugar, las diferencias, e incluso a veces contradicciones, que pueden producirse entre la escena política y el bloque en el poder y, en segundo lugar, que el poder no es detentado en solitario por una clase o fracción de clase, y mucho menos en una situación como la de España en aquellos momentos, con una importante presencia política, económica e ideológica de las antiguas clases aristocráticas.

El segundo error consiste en esa tajante constatación del fracaso de la burguesía. En realidad no hay un modelo fijo de dominio de la burguesía, al igual que no lo hay de revolución burguesa, y muy lejos de manifestar ese fracaso de la burguesía española, la revolución de 1868 y su posterior culminación en 1874 - se trata, ya los hemos dicho, de las dos caras de una misma moneda - muestran una admirable consolidación del poder burgués, compartido, claro está, con otras clases y fracciones. Ni siquiera con una visión reduccionista de la burguesía que identifique al conjunto de la misma con su fracción industrial ${ }^{20}$ puede hablarse de tal fracaso ya que, como veremos más adelante, dicha fracción obtuvo también sus contrapartidas y su consolidación en el bloque en el poder aunque, lógicamente, adaptándose

Sobre la polémica acerca de la revolución burguesa en España nos parece definitiva, por el momento, la excelente síntesis de PÉrEz Garzón, J. S., La revolución burguesa en España: los inicios de un debate científico, en Historiografía española..., o. c., págs. 91-138. 
a las características de la formación social española y haciendo prevalecer sus propias deficiencias en una cuestión clave como el proteccionismo.

Volviendo a la cuestión que planteábamos inicialmente de por qué la progresiva reducción de la presencia en la escena política de la burguesía mueve a ésta a promover un cambio político en profundidad hemos de dar una doble respuesta: la primera de ellas es que se había producido un evidente desajuste entre los intereses generales del bloque en el poder y la representación del mismo en la escena política. Entiéndase bien, no es que los moderados estuviesen monopolizando la escena política, con el desplazamiento de los demás partidos, sino que este monopolio no se ejerció durante los años inmediatamente anteriores a la revolución de una forma satisfactoria para los intereses generales del bloque en el poder. La segunda respuesta es que ese desajuste entre los intereses del bloque en el poder en general y la representación de partidos en la escena política no podía ser resuelto sin el recurso a una mayor o menor violencia por razones históricas concretas como eran la inexistencia del sufragio universal, como instrumento de racionalización de los interes del bloque en el poder en el estado capitalista, las características del sistema político y la actitud de una de las piezas claves de dicho sistema: la Corona.

Para entender las características del desajuste entre el bloque en el poder y la escena política hay que analizar la composición y las particularidades que aquél presentaba desde comienzos del primer tercio del siglo XIX. Por los condicionantes de la reforma agraria liberal en España y por el tipo de trasformación que aquí se produce desde el estado absolutista al estado liberal, la clase de los grandes terratenientes ocupa un lugar destacado en el seno del bloque en el poder. Esa clase presenta una división en dos estratos o capas: la de la antigua aristocracia terrateniente y la de los grandes propietarios agrarios de nuevo cuño, resultado de los procesos de desvinculación y desamortizacion. ${ }^{21}$ Esta división en dos capas se fundamenta en razones de

21 Sobre las transformaciones agrarias de carácter liberal en España y sus relaciones con la revolución burguesa vil. FONTANA, J., o. c., págs. 149-184. 
tipo político e ideológico. La aristocracia terrateniente, aunque había transformado su derecho feudal sobre la tierra en propiedad burguesa, mantenía unas pautas de comportamiento político e ideológico proclives al mantenimiento de antiguos privilegios y mucho más cercanas al absolutismo que al liberalismo. ${ }^{22}$ Junto a los grandes terratenientes, la burguesía española, con sus distintas fracciones - agraria, industrial, comercial, bancaria y de negocios-, se integraba también en el bloque en el poder. Pero junto a esas divisiones de la burguesía puede considerarse que existía otra división, también fundada en una diferenciación de intereses económicos, que se superponía a esas fracciones de la burguesía, dando origen a lo que podemos denominar burguesía compradora y burguesia interior. ${ }^{23}$

Dentro de la burguesía compradora quedarían incluidos los sectores de la alta burguesía española con débil asiento económico propio en el país y que funcionaban principalmente como intermediarios comerciales y financieros para la penetración del capital extranjero, estando, lógicamente, profundamente interesados en una legislación económica de signo librecambista. La actividad de esta burguesía compradora presentaba un carácter eminentemente especulativo, concentrándose en los sectores financieros, bancarios y comerciales. Pero la cuestión del librecambio no interesaba solamente a la burguesía compradora sino que otros sectores burgueses, pertenecientes a lo que hemos denominado burguesía interior, eran también partidarios de una legislación librecambista. Tal es el caso de la burguesía industrial vasca, cuyos intereses económicos estaban estrechamente ligados a la exportación de mineral de hierro y a la importación de carbón, ${ }^{24} \mathrm{o}$ el de las burguesías agrarias y comerciales de la periferia interesadas en el aumento de las exportaciones y del comercio exterior.

La capa de nuevos grandes propietarios de origen burgués, aunque distinta en sus orígenes presentaría una tendencia a la asimilación con la antigua aristocracia.

La denominación es totalmente convencional. Fernández de CASTRO, I., De las Cortes de Cádiz al posfranquismo, I, Barcelona, 1981, pág. 102. 
Junto a la cuestión clave del librecambismo hay que referirse, obligadamente, al tema de los ferrocarriles. Como es bien sabido, amplios sectores de la burguesía española y de las capas medias con capacidad de ahorro mantenían una relación estrecha con los negocios ferroviarios. ${ }^{25}$ No es el momento de extenderse en las profundas consecuencias económicas de la crisis ferroviaria de 1866 pero sí de señalar la gran conexión existente entre el mundo de los ferrocarriles y el mundo de la política, ${ }^{26}$ no sólo por la presencia en los consejos de administración de las principales compañías de importantes figuras políticas -muchas de ellas estrechamente ligadas al movimiento revolucionario de 1868- sino sobre todo por la peculiar forma de construcción de la red ferroviaria española en la que pesó mucho más la voluntad política que las propias exigencia del desarrollo económico. Cuando llegó la crisis, lógicamente, la necesidad de aumentar el apoyo político del que ya habían gozado los ferrocarriles españoles se hizo imprescindible para todos aqueIlos sectores sociales que tenían depositado en ellos sus intereses económicos. Esa aspiración se estaba viendo defraudada durante los meses inmediatamente anteriores a la revolución y cuando por fin, a comienzos de 1868 , se estaba discutiendo en las Cortes una subvención a los ferrocarriles de sesenta millones de reales fueron cerradas éstas por González Bravo, cundiendo al desánimo de todos los sectores con intereses ligados al ferrocarril. ${ }^{27}$

Hay que señalar, además, que, en vísperas de la revolución de 1868, la situación financiera del Estado era lamentable. Los años de mayor prosperidad de la década de los sesenta podían haber sido utilizados para aumentar la presión tributaria, pero no se hizo y fue en 1867 cuando el gobierno Narváez cometió la imprudencia de reforzar dicha presión, lo que contribuyó a enajenar el apoyo de los terratenientes, sobre cuyos hombros debía recaer en gran parte la misma. ${ }^{28}$

Vid. Tortella Casares, G., Los origenes del capitalismo en España, Madrid, 1975, págs. 9-17. Cf. FontanA, J., o. c., págs. 114-123.

Ibídem, pág. 122.

SÁNCHEZ ALBORNOZ, N., "El trasfondo económico de la revolución», Revista de Occidente, VI, 1968, 67, pág. 60. 
Así pues, la revolụción de 1868 responde a la necesidad de superar el desajuste entre los intereses de sectores mayoritarios del bloque en el poder y una escena política que, monopolizada por los moderados, se había autonomizado totalmente con respecto a dichos intereses. Como ya se ha dicho, ese desajuste no podía ser resuelto sin el recurso a una mayor o menor violencia por las propias limitaciones y la falta de viabilidad del sistema político imperante para permitir la racionalización de las contradicciones y de los conflictos en el seno del bloque en el poder. Ahora bien, la necesidad de superar el marco legal podía haberse traducido en un distinto abanico de actuaciones: desde la simple presión por la via de un pronunciamiento clásico que posibilitase la participación de los partidos excluidos hasta el cambio constitucional con el mantenimiento de Isabel II en el trono. El análisis de las intentonas progresistas durante los años anteriores a la revolución muestra que en un primer momento se confiaba en el típico pronunciamiento que obligase a la Corona a llamar a los progresistas al Gobierno y que sólo tras el levantamiento de los sargentos del cuartel de San Gil, en el verano de 1866, alcanza el proyecto revolucionario una dimensión y un alcance de mayor envergadura. ${ }^{29}$ Este acontecimiento marcó, sin duda, el límite de las posibilidades de un pronunciamiento clásico, señalando, al mismo tiempo, una radicalización del proceso revolucionario que se manifiesta tanto en la participación popular como en el aislamiento represivo del Gobierno y la Corona.

Como ha señalado Fontana, ${ }^{30}$ la experiencia de una serie de pronunciamientos fallidos sirve para convencer a Prim y sus compañeros de que el cambio político no podrá producirse con la ayuda de un puñado de soldados, lo que mueve a los promotores de la revolución a organizar un movimiento revolucionario en el que participen, también, las masas populares. Ahora bien, la posibilidad de implicar a sectores populares en el movimiento revolucionario significaba que estos sectores tenian que estar en condiciones de ser instrumentalizados, lo que efectivamente 
ocurría ya que junto al descontento burgués que hemos analizado anteriormente existía también un profundo descontento popular. Esta es, probablemente, una de las facetas más interesantes de la revolución del sesenta y ocho al confluir en ella diversos proyectos revolucionarios en torno a un eje fundamental. Puede decirse que, junto a una revolución política de la burguesía, el sesenta y ocho responde, en parte, al proyecto político de la pequeña burguesía democrática, que realiza también su experiencia revolucionaria, presentando, de igual modo, aspectos de revolución popular del campesinado y del proletariado industrial. Es más, puede decirse que la revolución de 1868 es el último movimiento revolucionario en el que esas clases populares actúan simplemente como fuerzas de apoyo de los partidos burgueses y pequeños burgueses y que el proceso revolucionario abierto en ese año coincide con la toma de conciencia de esas clases populares que, a partir de aquí, comenzaran a fijarse objetivos propios y diferenciados de los sectores democráticos de la burguesía y de la pequeña burguesía. ${ }^{31}$

Lo cierto es que con anterioridad al sesenta y ocho esa decantación de las clases populares hacia un espacio político e ideológico propio no se había producido todavía y, lógicamente,

31 Esa transformación en las prácticas políticas e ideológicas de las clases populares españolas fue consecuencia de la coincidencia de dos factores, uno de índole interna y otro de índole externa. El primero de ellos fue el propio proceso revolucionario abierto en 1868 que actuó como elemento clarificador en dos etapas sucesivas: la primera de ellas marcada por el incumplimiento de las promesas de los partidos burgueses y la polarización de los sectores populares en torno al republicanismo; la segunda por la superación del republicanismo como objetivo final, cuando las contradicciones y las vacilaciones de la pequeña burguesía cavaron un foso entre dicha ideología y las aspiraciones sociales y económicas de los trabajadores, formuladas, cierto es, de una manera imprecisa, utópica e inmadura, pero indicando ya el comienzo de un proyecto autónomo y diferenciado que abriría el segundo ciclo revolucionario de la España contemporánea. Es evidente, sin embargo, que ello no se hubiese producido sin la confluencia de un factor de índole externa como fue la llegada a España de la influencia de la I Internacional en su modalidad bakuninista. Y también puede decirse lo inverso, es decir, que el arraigo del anarquismo en nuestro país, es decir, esa gran excepción de España en el panorama de los movimientos obreros europeos, fue producto de que la llegada de esa influencia coincidió con la etapa revolucionaria del sesenta y ocho con la que se culminaba la frustración y la pérdida de confianza en la acción política de las clases populares españolas. 
dichas clases jugaron el papel de clases-apoyo, es decir, de clases que no obtuvieron ningún tipo de compensación por parte del bloque en el poder y que actuaron movidas bien por una especie de espejismo ideólogico - caso del republicanismo-, bien por unas promesas de carácter social y económico que no se cumplieron o se cumplieron muy defectuosamente.

El potencial revolucionario de dichos sectores estaba determinado por su lamentable situación económica y social y por la carencia de los más elementales derechos, cuestión esta última particularmente importante para los obreros industriales. ${ }^{32}$ Por lo que se refiere al campesinado y, más concretamente, a los jornaleros sin tierra el análisis de la estructura socio-profesional muestra que este último grupo aumentó considerablemente a lo largo del siglo XIX como consecuencia, sin duda, de las reformas agrarias liberales y de la escasa capacidad de absorción de excedentes humanos de la industria española. Dicho aumento culminó en la década de los sesenta, estabilizándose, a partir de aquí, el número de jornaleros sin tierra. Según Fernández de Castro ${ }^{33}$ la población de jornaleros en los años sesenta se cifraba, aproximadamente, en unos dos millones, cantidad igual a la del año 1900 y muy similar a la de 1931. Ese mantenimiento indica que dicho grupo había alcanzado un techo demográfico impuesto por su situación miserable, de tal manera que toda nueva incorporación resultaba biológicamente imposible, solucionándose el problema de los excedentes a través de la emigración, la incorporación a otros sectores y la eliminación física por el hambre o las epidemias. Esas cifras indican que, en vísperas de la revolución de 1868 , se había llegado a una situación de equilibrio inestable que tenía que traducirse en un máximo de tensión campesina. ${ }^{34}$ Por si esa situación estructural del campo no bastase, en vísperas del sesenta y ocho se produjo una crisis agraria de tipo antiguo, es decir, una crisis de subsistencias, que dio

Vid. Seco Serrano, C., La toma de conciencia de la clase obrera y los partidos políticos de la era isabelina, dentro de La revolución de 1868; historia, pensamiento y literatura, 1970 , págs. 39 y ss. FERnÁNDEZ de CASTRO, I, o. c., pág. 99.

34 Esa tensión había adquirido gran envergadura a partir de 1861, con la llamada sublevación de Loja, y fue creciendo a lo largo de los años sesenta. 
tintes dramáticos a la situación. El desencadenamiento y las consecuencias de dicha crisis han sido estudiados por Sánchez Albornoz, ${ }^{35}$ estableciendo una comparación con el modelo clásico de Labrousse para Francia. Prescindiendo ahora de esas posibles similitudes, de lo que no hay duda es que la crisis de subsistencias agravó considerablemente el malestar campesino y si no causa de la revolución sí fue, al menos, un factor condicionante de la misma al producir una situación de enorme deterioro social y al obligar a los dirigentes de la revolución, aunque sólo fuera nominalmente, a buscar una serie de satisfacciones a ese descontento.

El análisis de la dinámica revolucionaria del sesenta y ocho sirve para descubrir dos características fundamentales de la revolución que actúan, al mismo tiempo, como factores condicionantes de la misma: la heterogeneidad social de los participantes y el papel hegemónico jugado por la burguesía. Ello hace que a lo largo del proceso revolucionario se produzcan diversas expectativas para que, al final, se impongan los intereses de la propiedad por encima de cualquier otro objetivo de trasformación social o económica. Durante los primeros momentos de la revolución se manifiestan ya las tensiones y las contradicciones que aflorarán, con más virulencia, en el año 1873, mostrando los distintos planteamientos de los diversos grupos sociales que participaron en la revolución, y el control permanente de la misma ejercido por la burguesía. El ejemplo de las juntas revolucionarias resulta altamente significativo: al principio los manifiestos de las juntas son de un radicalismo extremo que incita al pueblo a la revuelta y a levantarse en armas, ${ }^{36}$ pero una vez que se ha tomado el poder se pasa a una fase distinta de defensa de la revolución victoriosa frente a sus enemigos, pero no de enemigos que se presentasen bajo el aspecto de fuerzas reaccionarias y contrarrevolucionarias sino como fuerzas que utilizarian la táctica de incitar al pueblo con falsos objetivos extremistas contrarios al mantenimiento y la defensa de la propiedad y el orden. ${ }^{37}$ La constitución del gobierno provisional encauza defi-

SÁnChez Albornoz, N., o. c., págs. 39 y ss.

Bozal, V., Juntas revolucionarias, manifiestos y proclamas de 1868, págs. 73-76.

lbídem, págs. 120-121. 
nitivamente la situación, reforzándose a partir de aquí las consignas de orden y sensatez que culminan con el desarme de aquellos que habían hecho posible el triunfo revolucionario. ${ }^{38}$

Por si la propia dinámica política de la revolución del sesenta y ocho no bastara para mostrar su auténtico significado, nada puede haber tan clarificador como el estudio de las consecuencias económicas del triunfo revolucionario. ${ }^{39}$ Puede decirse que la revolución de 1868 ha sido una de las pocas revoluciones que ha hecho subir la bolsa, ${ }^{40}$ despertando al mismo tiempo una acogida entusiasta en la prensa y en los círculos financieros, tanto nacionales como internacionales. Esa favorable disposición era indicativa de que la revolución podía ser beneficiosa en la regularización del pago de la deuda y en las subvenciones a las compañías ferroviarias, cuestiones ambas estrechamente ligadas a los intereses de la burguesía compradora española. La rápida resolución de dichas cuestiones indica claramente el papel dirigente de dicha burguesía en la revolución del sesenta y ocho.

Pero la solución del problema de la deuda y de los ferrocarriles españoles"presentaba importantes dificultades. En primer lugar porque la Hacienda española se encontraba en situación de acusado déficit y, en segundo lugar, porque la propia dinámica revolucionaria hacía imposible recurrir a una presión fiscal generalizada. ${ }^{41} \mathrm{El}$ hombre encargado de resolver el problema fue Laureano Figuerola, ministro de Hacienda, y su propia actuación indica los límites, las contradicciones y el condicionamiento social de la revolución del sesenta y ocho. Figuerola era el más claro representante del liberalismo económico español, ideología que, al menos teóricamente, inspiraba el aspecto económico del movimiento del sesenta y ocho desde el punto de vista burgués.

38 Ibidem, págs. 118-119.

39 Un análisis general de los efectos de la revolución en la política económica española puede verse en el capítulo VIII de la obra de TORTELLA CASARES, G., Los origenes del capitalismo..., págs. 293-317.

40 Tanto en la Bolsa de Madrid, como en las de París y Londres la cotización de la deuda pública española experimentó un alza apenas conocida la sublevación.

41 La actuación contra determinadas cargas tributarias, como los consumos, había sido una de las principales consignas revolucionarias. 
Desde la perspectiva del liberalismo económico resultaba una aberración cualquier medida de carácter intervencionista por parte del Estado. Pero no sólo las restrictivas, es decir, las que se opusieran a la libertad más amplia en la esfera económica, sino también cualquier otra medida de ayuda o subvención a determinados sectores económicos, como podía ser el caso del ferrocarril. Las propias palabras de Figuerola en el preámbulo del decreto que otorgaba ayuda económica a los ferrocarriles españoles son altamente expresivas de ese planteamiento:

El ministro que suscribe no hubiera propuesto el auxilio que Gobiernos anteriores ofrecieron a las empresas de ferro-carriles, después de las cuantiosas subvenciones que se les otorgaron en las respectivas leyes de concesión; porque considera que la resolución definitiva de la cuestión de ferro-carriles no consiste en dar nuevas subvenciones, $\mathrm{ni}$ deben ser los contribuyentes responsables de los errores de apreciación de las empresas, y de las consecuencias de su gestión, no siempre, acaso, tan económica y acertada como hubiera sido de desear.

Los verdaderos medios de mejorar la situación de los ferrocarriles son aquellos que, realizando la libertad de la industria y del tráfico, desarrollan la riqueza general de los pueblos, restringiendo la intervención inmotivada y molesta del Estado... ${ }^{42}$

Y siendo así, ¿por qué esa subvención? La justificación de Figuerola era que los anteriores gobiernos se habían comprometido en una subvención que no había sido llevada a la práctica. ¿Se pueden tomar en serio estas palabras? La verdad es que no; si se estaba en contra de una determinada política y se habia puesto fin de una manera revolucionaria al gobierno y al régimen que la sustentaba no había ningún tipo de justificación para ello. Los hechos demuestran más bien todo lo contrario; demuestran que uno de los factores que contribuyeron con más intensidad al desencadenamiento del movimiento revolucionario del sesenta y ocho fue la no materialización de esa subvención en la que estaban enormemente interesados tanto la burguesía compradora española como los sectores del capitalismo internacional con intereses financieros y ferroviarios en España. Lo que quedaba claro es que los sectores que habian propiciado un cambio 
en la escena política - un cambio que favoreciese sus intereses - no iban a consentir que bajo los principios del liberalismo económico no se diera satisfacción a los mismos. El liberalismo económico era necesario y era defendido por esos sectores en otras facetas de la vida económica en que su aplicación resultaba beneficiosa. Pero cuando entraban en colisión con esos intereses, los grandes principios del liberalismo económico debían ser abandonados y, en ese sentido, el gobierno revolucionarıo respondió adecuadamente a las presiones de la burguesía compradora española, la fracción social más beneficiada por la revolución. ${ }^{43}$

Si en el caso de los ferrocarriles los intereses de la burguesía compradora española y del capitalismo financiero internacional exigían el intervencionismo estatal, en otros campos las exigencias se orientaban hacia una total liberalización. Ese fue el caso de la minería española que experimentó, a partir de 1868 y gracias a la nueva orientación de la política económica, una profunda trasformación. Hasta ese momento la explotación minera en España se habia mantenido en un estado de letargo debido en parte a causas económicas ${ }^{44}$ pero también, en buena medida, a razones de orden político que habían frenado una posible expansión del sector como consecuencia de la excesiva rigidez de las concesiones y el excesivo control de las mismas. A partir de la revolución de 1868 el panorama cambió totalmente: la aplicación del más estricto liberalismo económico sí que interesaba en este sector tanto a la burguesía financiera internacional como a los sectores de la burguesía española ligados a la misma. La liberación de la minería española adquiría un carácter

43 No sólo este sector de la burguesía jugó cartas en el asunto sino que también los sectores financieros del capitalismo internacional con intereses en España hicieron oír sus voces con meridiana claridad. El condicionamiento que esos sectores exteriores podian imponer a la política económica del gobierno eran de un extraordinario calibre ya que para hacer frente a la situación financiera del país la hacienda española necesitaba imperiosamente un empréstito que sólo podía venir del exterior. Las relaciones con los Rothschild pueden ser un buen ejemplo de este condicionamiento: este grupo formaba parte, como más importante, de una serie de banqueros extranjeros con los que el gobierno revolucionario entró en contacto rápidamente para gestionar un empréstito; el grupo Rothschild exigió que el $15 \%$ de dicho empréstito se destinase a la subvención de las compañías ferroviarias, a lo que no tuvo más remedio que acceder Figuerola.

44 Vid. NADAL, J., El fracaso de la revolución industrial en España, 1814-1913, Barcelona, 1975, págs. 87-121. 
imperativo para dichos sectores desde el momento en que la industrialización se había generalizado en toda Europa y la necesidad de minerales por parte de la industria podía ser fuente de importantes y fáciles beneficios. ${ }^{45}$

¿Qué otras medidas económicas adoptaron los gobernantes del sesenta y ocho? En primer lugar una serie de medidas tendentes a la liberación del crédito y las finanzas que suprimieron las normas restrictivas que todavía pesaban sobre bancos, sociedades de crédito y sociedades anónimas, limitando al máximo cualquier intervención estatal sobre las mismas. En segundo lugar se tomaron medidas para homogeneizar a España desde el punto de vista monetario con otros paises europeos, ${ }^{46} \mathrm{ha}$ ciendo de la peseta la nueva unidad monetaria española. Estos dos bloques de medidas resultaban también enormemente favorables tanto a la burguesía compradora española como a la burguesía internacional con intereses en España, al facilitar los negocios y las relaciones comerciales. Quedaba una última medida, importantísima desde el punto de vista del liberalismo económico, pero de mucho más difícil aplicación ya que podía originar divisiones en el seno del bloque en el poder: esa medida era la reforma arancelaria.

Hasta 1868, la política económica española se habia caracterizado por un acusado proteccionismo en el que estaban especialmente interesados la burguesía industrial catalana, los cerealistas castellanos y otros sectores no competitivos. ${ }^{47}$ En torno al librecambismo se agrupaban intereses no menos importantes tales como los del conjunto de la burguesía compradora con relaciones internacionales, la burguesía comercial de la periferia, importantes sectores de la burguesia agraria con intereses en la exportación, buena parte de la burguesía industrial vasca y, en fín, un numeroso y cualitativamente importante grupo de intelectuales, economistas, políticos y hombres de estado que consideraban el librecambismo una medida imprescindible

Otras fracciones de la burguesia española, como la burguesía industrial vasca, estaban también interesadas en el desarrollo y liberalización del sector minero. Vid. Tortella Casares, G., o. c., pág. 296 y ss.

47 La burguesía industrial catalana, a través del Fomento Nacional del Trabajo, arrastraba también a importantes sectores obreros, bajo la amenaza del paro que podía originar el librecambismo. 
para la modernización del país. La reforma arancelaria representaba, por tanto, un posible punto de fricción en el seno del bloque en el poder que exigía un compromiso y un intento de armonización de intereses contrapuestos. Pues bien, la reforma de los aranceles de 1869, a pesar de las acusaciones de ultraliberal de que ha sido objeto, responde claramente a ese compromiso ya que, aunque disminuyeron, las tarifas se mantuvieron lo suficientemente altas como para no inquietar excesivamente a los sectores partidarios del proteccionismo. El aspecto más positivo de la reforma - la disminución progresiva de las tarifas a partir del año 1875 hasta que no quedase ninguna por encima del $15 \%$ - no llegó a tener vigencia ya que seis meses antes de que entrara en vigor fue suspendida la base $V$ que la regulaba. De esta forma la Restauración, como culminación del sesenta y ocho, venía a consolidar el bloque en el poder, evitando posibles fisuras que pusieran en peligro su estabilidad.

A modo de conclusión, en la que resumimos los aspectos más esenciales de las páginas anteriores y en la que nos adentramos - aunque muy superficialmente- en nuevas hipótesis, podemos decir lo siguiente:

1. El desajuste entre la escena política y el bloque en el poder, agudizado en la década de los sesenta, se resuelve con la revolución de 1868. La misión de esa revolución era construir un nuevo marco de dominación política en el que pudieran expresarse de una manera más eficaz los intereses de las diferentes clases y fracciones del bloque en el poder y para ello resultaba imprescindible una democratización de la escena política y una racionalización del acceso a la misma a través de la introducción del sufragio universal.

2. La necesaria construcción de ese marco se vio enormemente condicionada por la inexistencia de una hegemonía clara en el conjunto del bloque en el poder, lo que llevaba a una serie de contradicciones que se reflejaban en la escena política y que originaron, a lo largo del sexenio, una gran inestabilidad política y gubernamental. Otro condicionante fue la agudización de las contradicciones entre el bloque dominante y el bloque dominado originada, en primer lugar, por las propias caracteristicas democráticas del proceso revolucionario y por la ampliación de la 
participación política que éste trajo consigo y, en segundo lugar, por coincidir dicho proceso con la etapa de inicio y despertar del movimiento obrero, como fuerza autónoma, y con la radicalización de otras capas intermedias, como la pequeña burguesía.

3. Ese doble haz de contradiciones culminó en el año 1873, cuando la forma de régimen que había mantenido hasta entonces el estado liberal quedó agotada, dándose paso a una nueva forma de régimen, la republicana, para la que resultaba imprescindible la alianza del bloque en el poder con la pequeña burguesia. ${ }^{48}$ Hay que tener en cuenta que a esa alianza se llega como última medida, es decir, como fruto de la no existencia de otra solución de recambio y que la misma significaba que la pequeña burguesía se convertía en clase reinante o gobernante, con la lógica misión de asegurar la hegemonía social del bloque en el poder sobre el conjunto de clases dominadas. Dicho en otras palabras: la experiencia de gobierno de la pequeña burguesía sólo podía ser duradera a medio plazo en el supuesto de que ésta lograse convertir en clase-apoyo a las clases dominadas, es decir, al proletariado industrial y agrícola.

4. Al ser incapaz la pequeña burguesía española de lograr esa hegemonía e incapaces también, por su parte, las clases dominadas de constituir una alternativa al estado capitalista, se producía una situación crítica que debía ser resuelta, evidentemente, por un aparato del estado. Esa resolución, materializada en las actuaciones de Pavía y Martínez Campos, llevaba a la restauración, que debe ser entendida como una culminación del sesenta y ocho, es decir, como la consolidación de un nuevo marco de dominación política, basado en la hegemonía de los sectores financieros y terratenientes dentro de un bloque en el poder en el que se armonizasen los intereses del conjunto de la burguesía española. Un político de indudable talla, Cánovas, logró esa consolidación, asegurando una larga etapa de estabilidad del estado liberal, bajo la forma monárquica, que duró hasta el mes de septiembre de 1923.

El término alianza se emplea aquí en sentido social y no como expresión de una coalición o acuerdo político. 